\title{
Identification of Lactobacillus plantarum genes modulating the cytokine response of human peripheral blood mononuclear cells
}

\author{
Saskia van Hemert ${ }^{1,2}$, Marjolein Meijerink ${ }^{1,3}$, Douwe Molenaar ${ }^{1,2,4}$, Peter A Bron ${ }^{1,2,5}$, Paul de Vos ${ }^{1,6}$, \\ Michiel Kleerebezem ${ }^{1,2,7}$, Jerry M Wells ${ }^{1,3}$, Maria L Marco $0^{1,2,8^{*}}$
}

\begin{abstract}
Background: Modulation of the immune system is one of the most plausible mechanisms underlying the beneficial effects of probiotic bacteria on human health. Presently, the specific probiotic cell products responsible for immunomodulation are largely unknown. In this study, the genetic and phenotypic diversity of strains of the Lactobacillus plantarum species were investigated to identify genes of L. plantarum with the potential to influence the amounts of cytokines interleukin 10 (IL-10) and IL-12 and the ratio of IL-10/L-12 produced by peripheral blood mononuclear cells (PBMCs).

Results: A total of 42 Lactobacillus plantarum strains isolated from diverse environmental and human sources were evaluated for their capacity to stimulate cytokine production in PBMCs. The L. plantarum strains induced the secretion of the anti-inflammatory cytokine IL-10 over an average 14-fold range and secretion of the proinflammatory cytokine IL-12 over an average 16-fold range. Comparisons of the strain-specific cytokine responses of PBMCs to comparative genome hybridization profiles obtained with L. plantarum WCFS1 DNA microarrays (also termed gene-trait matching) resulted in the identification of 6 candidate genetic loci with immunomodulatory capacities. These loci included genes encoding an N-acetyl-glucosamine/galactosamine phosphotransferase system, the LamBDCA quorum sensing system, and components of the plantaricin (bacteriocin) biosynthesis and transport pathway. Deletion of these genes in L. plantarum WCFS1 resulted in growth phase-dependent changes in the PBMC IL-10 and IL-12 cytokine profiles compared with wild-type cells.

Conclusions: The altered PBMC cytokine profiles obtained with the L. plantarum WCFS1 mutants were in good agreement with the predictions made by gene-trait matching for the $42 \mathrm{~L}$. plantarum strains. This study therefore resulted in the identification of genes present in certain strains of $L$. plantarum which might be responsible for the stimulation of anti- or pro-inflammatory immune responses in the gut.
\end{abstract}

\section{Background}

Metagenomics and host-microbe molecular interaction studies are rapidly expanding our understanding of the indigenous gut microbiota and the contributions of microbes to human health [1,2]. These efforts are complementary to the numerous reports describing health benefits associated with the ingestion of probiotic bacteria $[3,4]$. Probiotics are living microorganisms which confer health effects on the host when administered in

\footnotetext{
* Correspondence: mmarco@ucdavis.edu

'TI Food \& Nutrition, Nieuwe Kanaal 9A, 6709PA, Wageningen, The Netherlands

Full list of author information is available at the end of the article
}

sufficient amounts [5]. Strains of Lactobacillus and Bifidobacterium are the most commonly applied probiotics in food products. Members of these genera are residents of the human intestine and have a long history of safe use in foods and beverages. Health benefits conferred by probiotics can be specific to the gastrointestinal tract (e.g. protection against intestinal inflammation or enteric pathogens) or occur at peripheral mucosal sites in the human body (e.g. prevention of allergy or dermatitis) [6].

There is substantial evidence that an important mechanism by which probiotics provide health benefits is through modulation of immune functions [7-11]. Differences among probiotic strains to stimulate immune

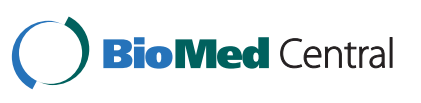

(c) 2010 van Hemert et al; licensee BioMed Central Ltd. This is an Open Access article distributed under the terms of the Creative Commons Attribution License (http://creativecommons.org/licenses/by/2.0), which permits unrestricted use, distribution, and reproduction in any medium, provided the original work is properly cited. 
cells towards pro- and anti-inflammatory responses have been shown in studies measuring cytokine production in vitro [7-11]. These comparisons have resulted in the identification of strains inducing similar responses in vivo. For example, ratios of IL-10 to IL-12 produced by Peripheral Blood Mononuclear Cells (PBMCs) in response to different probiotics in vitro were correlated to their protective capacity in a mouse model of colitis [10]. Similarly, recent studies on the mechanisms of probiotics highlight their effects on epithelial barrier function via Toll-like receptor 2 signaling and the generation of regulatory dendritic cells and regulatory CD4+Foxp3+ $\mathrm{T}$ cells in peripheral tissues [12,13]. The latter mechanism is linked to the administration of a collection of five strains which induced a high IL-10/IL-12 ratio in coculture with immune cells [12]. Administration of these strains was shown to have a therapeutic effect in experimental mouse models of inflammatory bowel disease, atopic dermatitis, and rheumatoid arthritis and was associated with enrichment of CD4(+)Foxp3(+) Tregs in the inflamed regions [12].

The cell products of probiotics that are responsible for modulation of cytokine induction are largely not known but might involve modifications of some of the known Microbe Associated Molecular Patterns (MAMPs) such lipoteichoic acids (LTA) [14-16] and (lipo)proteins localized on the bacterial cell surface [17] which interact with Toll-like receptors. Additionally cell-surface associated bacterial glycosylated proteins or exopolysaccharides [18] may interact with other host pattern recognition receptors including the $\mathrm{C}$-type lectins and scavenger receptors found on antigen presenting cells [19]. These extracellular and secreted products produced by probiotic cells are the likely targets for strain-dependent interactions with host cells and have been the focus of several recent reviews $[6,20,21]$.

Certain strains of Lactobacillus plantarum are marketed as probiotics and reported to confer various health effects including immunomodulation [22]. The genome sequence of L. plantarum strain WCFS1 is known [23] and extensive bioinformatics tools [24,25], molecular models [26], and a database of genome hybridization profiles $[27,28]$ are available for this organism. It is a single colony isolate of strain NCIMB8826, which was shown to survive gastrointestinal passage after oral administration to healthy volunteers [29]. Global gene expression profiling of L. plantarum WCFS1 in the intestinal contents of the human gut and conventionally-raised and germ-free mice has shown that this organism adapts for growth in vivo by modification of its cell-surface composition and metabolism in a dietdependent manner [30-34]. Human duodenal transcriptional response profiles have also been obtained in response to ingestion of $L$. plantarum WCFS1 [35,36].
Notably, exponential phase and stationary phase L. plantarum WCFS1 cells elicited distinct human duodenal transcript profiles which appeared to mainly result from differential modulation of canonical NF- $\kappa \beta$ dependent signaling pathways associated with immune tolerance [35].

The aim of the present study was to identify genes involved in immunomodulation by L. plantarum WCFS1. The IL-10 and IL-12 cytokine levels elicited by peripheral blood mononuclear cells (PBMCs) upon stimulation with L. plantarum WCFS1 and 41 other Lactobacillus plantarum strains were determined. We compared the IL-10 and IL-12 stimulating phenotypes of each strain to its genome composition determined by comparative genome hybridization $(\mathrm{CGH})$ to identify candidate L. plantarum genes with the capacity to affect cytokine production in PBMCs. The immunomodulatory potential of these gene products was confirmed for L. plantarum WCFS1 gene deletion mutants and found to be dependent on the growth-phase of the L. plantarum cultures.

\section{Results}

Immunomodulation of PBMCs is a variable phenotype in L. plantarum

A total of 42 L. plantarum strains from distinct (fermented) food, environmental, and gastrointestinal sources (Table 1 and $[27,28]$ ) were investigated for their capacities to stimulate PBMCs to produce the cytokines IL-10 and IL-12. Comparisons of cytokine amounts induced among different donors in response to the $L$. plantarum strains showed that the L. plantarum cultures induced a similar range of IL-10 but up to 10-fold different levels of IL-12 (Figure 1). This result is agreement with previous studies showing that PBMCs respond differently depending on the donor from which the cells were isolated [37]. However, the capacity of individual L. plantarum strains to induce cytokines production in PBMCs was similar among the different donors relative to the other strains tested. For example, $L$. plantarum KOG18 consistently induced the highest amounts of IL-12 whereas strain CIP104448 induced the highest ratios of IL-10 to IL-12. Collectively, the 42 L. plantarum strains induced, on average, IL-10 and IL-12 in PBMCs over a 14- and 16 - fold range, respectively, and IL-10/IL-12 ratios over a 13.5 - fold range (Figure 1). Strain WCFS1 induced relatively low IL-10 amounts (between 440 and $780 \mathrm{pg} / \mathrm{ml}$ ), moderate amounts of IL-12 (between 20 and 260 pg/ml), and consequently a moderate to low IL-10/IL-12 ratio (bottom quartiles) compared with the other strains (Figure 1).

\section{Identification of candidate genes involved in immunomodulation}

To identify candidate $L$. plantarum genes involved in the modulation of the immune response, Random Forest 
Table 1 L. plantarum strains selected for genotyping and screening for immunomodulatory capacity

\begin{tabular}{|c|c|c|c|}
\hline Strain & Strain ID & Isolation source & $\begin{array}{l}\text { Geographical } \\
\text { origin }\end{array}$ \\
\hline WCFS1 & NIZO1836 & Human saliva & n.a. \\
\hline LP80 & $\mathrm{NIZO} 2263$ & Silage & n.a. \\
\hline Lp95 & $\mathrm{NIZO} 2814$ & Wine red grapes & Italy \\
\hline CIP102359 & CIP102359 & Human spinal fluid & France \\
\hline ATCC8014 & NIZO2726 & Maize ensilage & n.a. \\
\hline LD3 & NIZO2891 & Radish pickled & Vietnam \\
\hline CHEO3 & NIZO2457 & $\begin{array}{l}\text { Pork pickled sour } \\
\text { sausage }\end{array}$ & Vietnam \\
\hline LD2 & NIZO2535 & Orange fermented & Vietnam \\
\hline BLL(EI31) & NIZO2830 & n.a. & Not known \\
\hline CIP104452 & $\mathrm{NIZO} 2259$ & Human tooth abscess & France \\
\hline $\begin{array}{l}\text { CECT221 } \\
(24 A b 04)\end{array}$ & NIZO2831 & Grass silage & United States \\
\hline LM3 & $\mathrm{NIZO} 2262$ & Silage & n.a. \\
\hline $\mathrm{NCTH} 27$ & $\mathrm{NIZO} 2494$ & $\begin{array}{l}\text { Pork pickled sour } \\
\text { sausage }\end{array}$ & Vietnam \\
\hline NCDO1193 & NCDO1193 & Vegetables & n.a. \\
\hline LMG9208 & NIZO2806 & Sauerkraut & United Kingdom \\
\hline ATCC14917 & NIZO2896 & Cabbage pickled & Denmark \\
\hline NOS140 & $\mathrm{NIZO} 2741$ & Cabbage kimchi & Japan \\
\hline 299 & NIZO1837 & Human colon & United Kingdom \\
\hline N58 & NIZO2855 & $\begin{array}{l}\text { Pork pickled sour } \\
\text { sausage }\end{array}$ & Vietnam \\
\hline $\mathrm{X} 17$ & NIZO2877 & Hot dog & Vietnam \\
\hline 299v/DSM9843 & $\mathrm{NIZO} 2260$ & Human intestine & United Kingdom \\
\hline MLC43 & NIZO2029 & $\begin{array}{l}\text { Raw cheese with } \\
\text { rennet }\end{array}$ & Italy \\
\hline LAC7 & NIZO2889 & Banana fermented & Vietnam \\
\hline LP85-2 & NIZO2264 & Silage & France \\
\hline NCTH19-1 & $\mathrm{NIZO} 2484$ & $\begin{array}{l}\text { Pork pickled sour } \\
\text { sausage }\end{array}$ & Vietnam \\
\hline NCTH19-2 & NIZO2485 & $\begin{array}{l}\text { Pork pickled sour } \\
\text { sausage }\end{array}$ & Vietnam \\
\hline NC8 & NIZO2261 & Grass silage & Sweden \\
\hline KOG24 & $\mathrm{NIZO} 2802$ & Cheese & Japan \\
\hline KOG18 & $\mathrm{NIZO} 2801$ & Turnip pickled & Japan \\
\hline LMG18021 & NIZO3400 & Milk & Senegal \\
\hline Q2 & NIZO2753 & Sourdough fermented & Italy \\
\hline SF2A35B & NIZO1839 & Sour cassava & South America \\
\hline CIP104451 & $\mathrm{NIZO} 2258$ & Human urine & France \\
\hline CIP104450 & NIZO2257 & Human stool & France \\
\hline CIP104448 & CIP104448 & Human stool & France \\
\hline DKO22 & NIZO2897 & Sour cassava & Nigeria \\
\hline $\mathrm{H} 14$ & NIZO2766 & Sourdough fermented & Italy \\
\hline $\mathrm{H} 4$ & $\mathrm{NIZO} 2757$ & Sourdough fermented & Italy \\
\hline CECT4645 & $\mathrm{NIZO} 2776$ & Cheese & n.a. \\
\hline CIP104441 & $\mathrm{NIZO} 2256$ & Human stool & France \\
\hline CIP104440 & NIZO1838 & Human stool & France \\
\hline NCIMB12120 & NIZO1840 & Cereal fermented (Ogi) & Nigeria \\
\hline
\end{tabular}

n.a. not available.

a See references $[27,28]$ for comparative genome hybridization analyses of these strains. models [38] were used to compare L. plantarum CGH profiles with the relative amounts of IL-10 and IL-12 and IL-10/IL-12 ratios induced by the strains in coculture with PBMCs (Figure 1). PBMCs from different donors incubated with replicate $L$. plantarum cultures were used for these models to take into account the levels of variation in cytokine production. Comparisons of $L$. plantarum strain genotype to the IL-10-stimulating capacities resulted in the identification of 6 different chromosomal loci and a total of 13 genes that might influence IL-10 production (Table 2). In comparison, concise correlations between $L$. plantarum CGH profiles and IL-12 amounts were not found. One of the genes correlated with IL-10 amounts was L. plantarum WCFS1 lp_1953. L. plantarum strains harboring this gene stimulated the production of IL-10 in 1.6-fold higher amounts, on average, compared to L. plantarum strains for which this gene was absent. Lp_1953 encodes a hypothetical intracellular protein of unknown function [25]. The remaining five genes with putative roles in IL-10 modulation comprise a putative 5 gene operon (lp_2647 to lp_2651) encoding Pts19ADCBR, an $\mathrm{N}$-acetyl-galactosamine/glucosamine phosphotransferase system (PTS). Strains harboring these genes were associated with induction of lower amounts of IL-10 by PBMCs.

Comparisons between L. plantarum strain-specific CGH profiles and IL-10/IL-12 ratios from PBMCs resulted in the identification of four L. plantarum WCFS1 loci which correlated with IL-10/IL-12 values (Table 2). L. plantarum WCFS1 plnEFI and $p \ln G$ (lp_419-423) and lamB (lp_3582) were most commonly present in strains stimulating low IL-10/IL-12 ratios. These genes are under the control of the auto-inducing peptide (AIP)-based quorum sensing (QS) twocomponent regulatory systems (QS-TCSs) found in $L$. plantarum $[39,40]$. The genes $p \ln E F I$ and $p \ln G$ encode two bacteriocin peptides, a bacteriocin immunity protein, and an ATP - Binding Cassette $(\mathrm{ABC})$ transporter $[23,41]$. The $\operatorname{lamB}$ is the first gene in the L. plantarum lamBDCA operon and shows $30 \%$ amino acid identity to the $S$. aureus AgrD-processing protein AgrB required for AIP modification and export [39]. The other $L$. plantarum genes associated with specific IL-10/ IL-12 ratios are lp_2460 and lp_2480 coding for prophage R-Lp3 remnant proteins $\mathrm{P} 2 \mathrm{~b}$ protein 21 and 1 , respectively [23]. These genes are conserved among L. plantarum strains stimulating high IL-10/IL-12 ratios in PBMCs. The functions of prophage R-Lp3 and other complete prophages in L. plantarum WCFS1 genome are not known [42]. Because the different prophages found in L. plantarum WCFS1 share high levels of sequence homology and potential functional redundancy [42], these genes were not examined further. 


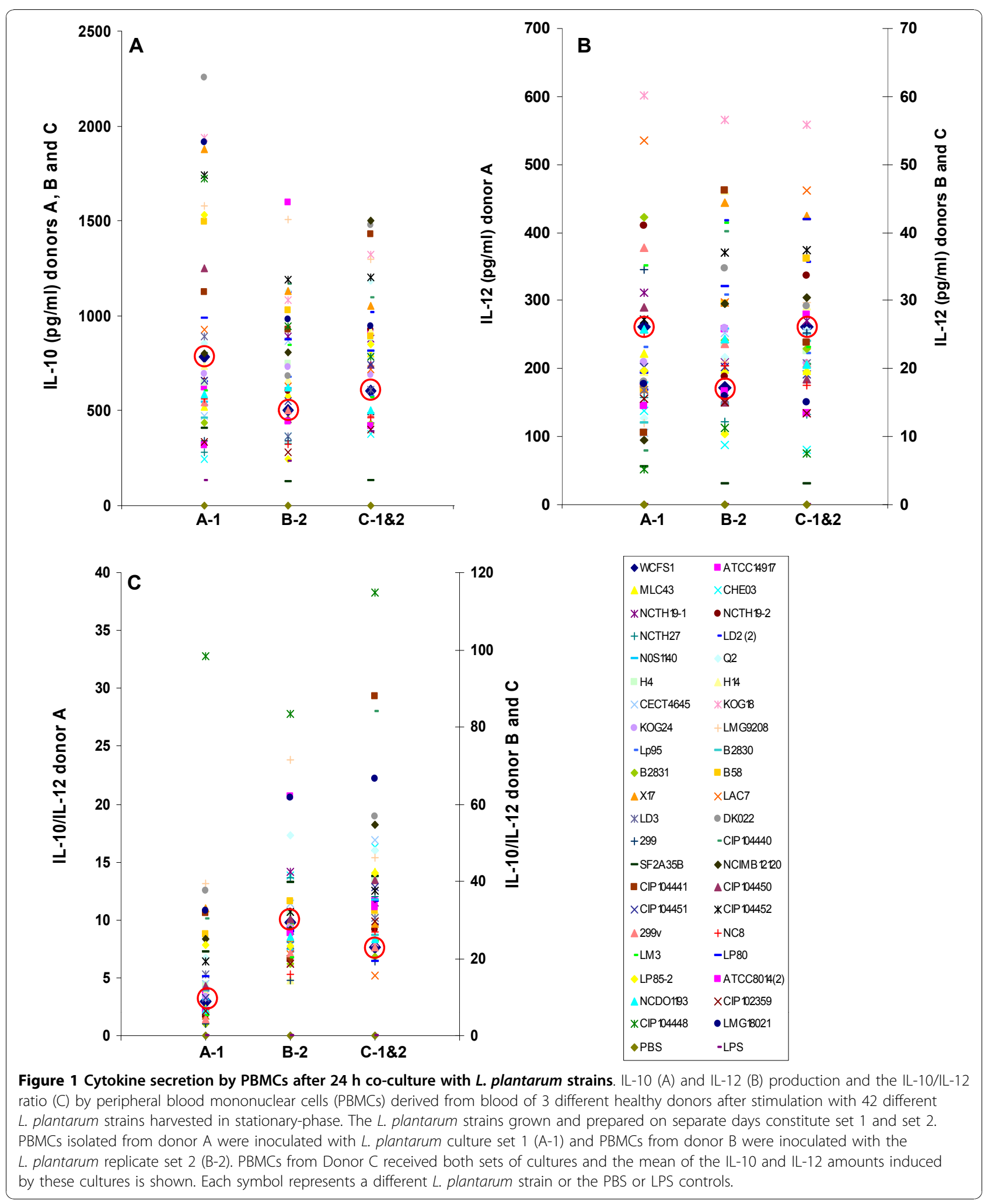


Table 2 L. plantarum genes with putative roles in modulating PBMC cytokine production.

\begin{tabular}{|c|c|c|c|c|c|}
\hline \multirow{2}{*}{$\begin{array}{l}\text { Genes(s) } \\
\text { p_1953 }\end{array}$} & \multirow{2}{*}{$\begin{array}{l}\text { Gene number }^{\mathbf{a}} \\
\text { Ip_1953 }\end{array}$} & \multirow{2}{*}{$\begin{array}{l}\text { Product } \\
\text { Hypothetical protein }\end{array}$} & \multirow{2}{*}{$\begin{array}{l}\text { Percent of strains } \\
\text { with the gene }(\mathbf{s})^{\mathbf{b}}\end{array}$} & \multicolumn{2}{|c|}{$\begin{array}{l}\text { Gene-dependent contribution to } \\
\text { cytokine stimulation }\end{array}$} \\
\hline & & & & IL-10 & 1.6-fold $\uparrow$ \\
\hline pts19ADCBR & Ip_2647-2651 & $\begin{array}{l}\text { N-galactosamine PTS, EIIADCB and } \\
\text { transcription regulator, GntR family }\end{array}$ & 33 & $\mathbb{I L}-10$ & 1.7-fold $\downarrow$ \\
\hline \multirow[t]{3}{*}{ plnEFl } & Ip_0419-0422 & Immunity protein PInl & $81-85$ & IL-10/IL-12 & 1.7-fold $\downarrow$ \\
\hline & & Bacteriocin-like peptide PInF & & & \\
\hline & & Bacteriocin-like peptide PInE & & & \\
\hline$p \ln G$ & Ip_0423 & $\mathrm{ABC}$ transporter & 88 & IL-10/IL-12 & 1.8-fold $\downarrow$ \\
\hline $\operatorname{lamB}$ & Ip_3582 & Accessory gene regulator protein & 43 & IL-10/IL-12 & 1.3-fold $\downarrow$ \\
\hline \multirow[t]{2}{*}{ prophage P2b 1 \& 21} & Ip_2460 & Prophage P2b protein 21 & 38 & IL-10/IL-12 & 1.5 -fold $\uparrow$ \\
\hline & Ip_2480 & Prophage $\mathrm{P} 2 \mathrm{~b}$ protein 1 , integrase & & & \\
\hline
\end{tabular}

${ }^{a}$ Gene number on the L. plantarum WCFS1 chromosome [23].

b Percentage of $L$. plantarum strains containing the gene according to $\mathrm{CGH}[27,28]$.

c Gene-trait matching importance measures (in parentheses) and predicted effects of the gene(s) on the variable and average magnitude and direction (higher or lower) of IL-10 and IL-10/IL-12 amounts.

\section{Verification of the roles of the candidate genes} in immunomodulation

To validate the influence of the candidate L. plantarum genes on PBMC cytokine responses, lp_1953, pts19AD$C B R, p \ln E F I$, and $p \ln G$ deletion mutants were constructed for L. plantarum WCFS1. A previously constructed L. plantarum WCFS1 lamA (lp_3580)lamR (lp_3087) double mutant was used to examine the potential roles of the $\operatorname{lamBCDA}$ QS-TCS on PBMCs. This strain was selected because $\operatorname{lam} A$ and $\operatorname{lam} R$ encode the response regulators of the 2 TCS (lamBCDA and $\operatorname{lamKR}$ ) regulating the expression of the LamD AIP

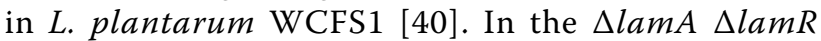
mutant, expression levels of $\operatorname{lam} B$ and the other genes in this operon were at $5 \%$ of the levels found in wildtype cells [40].

Wild-type and mutant $L$. plantarum WCFS1 cells harvested in the stationary- and exponential phases of growth were examined for their capacity to stimulate IL-10 and IL-12 in PBMCs. Overall, among the donors examined, IL-10 and IL-12 were produced in response to L. plantarum at levels between 500 to $4500 \mathrm{pg} / \mathrm{ml}$ and 3 to $68 \mathrm{pg} / \mathrm{ml}$, respectively (shown as $\log _{2}$ values in Figure 2 and 3). Notably, exponential cultures of wildtype L. plantarum WCFS1 and most mutant strains stimulated PBMCs to secrete higher amounts of IL-10 and IL-12 than stationary-phase cells (Figure 2 and 3).

L. plantarum strains harboring the $p \operatorname{lnEFI,~} \ln G$ or $\operatorname{lam} B$ loci were associated with the stimulation of lower IL-10/IL-12 ratios by L. plantarum in the PBMC assay (Table 2). In agreement with the gene-trait correlations, the $p \ln E F I, p \ln G$, and $\operatorname{lam} A \operatorname{lam} R$ deletion mutants of strain WCFS1 induced higher IL-10/IL-12 ratios than the wild-type strain (Figure 4 and Table 3 ). However, the effects of the plnEFI deletion on cytokine induction in different donors was not highly significant compared to wild-type $L$. plantarum when the $\mathrm{p}$ value was adjusted for multiple hypothesis testing (adjusted (adj.) $\mathrm{p}$ value $=0.071)$ (Figure 4 and Table 3$)$. Mutants deficient in the $\mathrm{ABC}$ - transporter $p \ln G$ induced significantly higher cytokine ratios compared with L. plantarum

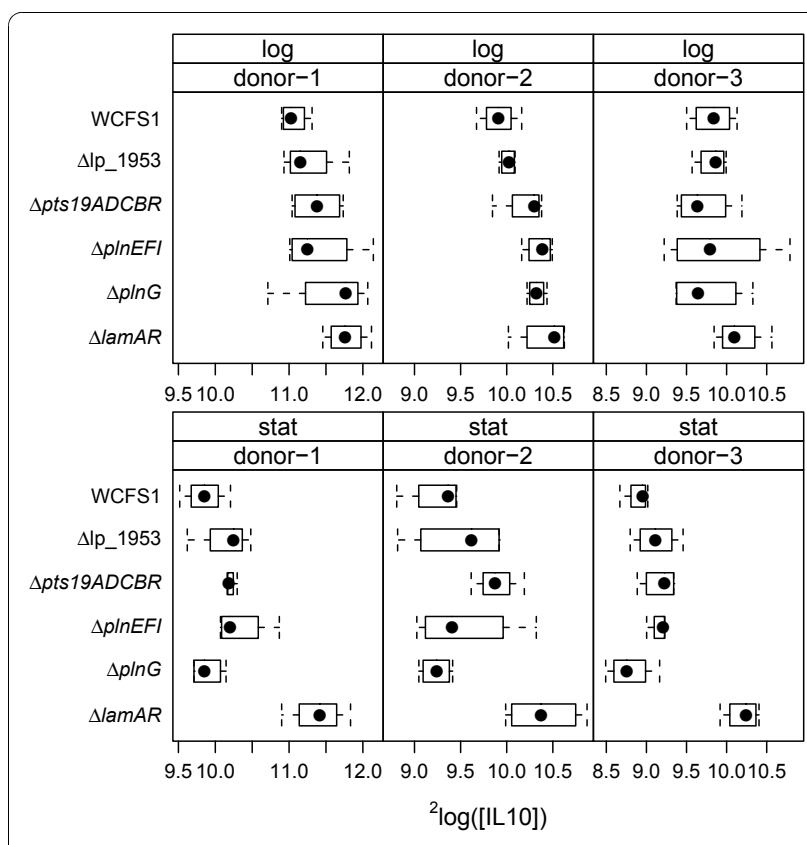

Figure 2 Boxplots of IL-10 amounts produced by PBMCs in response to $L$. plantarum wild-type and mutant cells. ${ }^{2} \mathrm{Log}$ transformed IL-10 amounts induced by exponential and stationary phase L. plantarum cells are shown. The dots indicate the median value, the boxes indicate first and third quartile, and the whiskers extend to outlying data points for a total of 12 measurements (3 PBMC donors were measured using 4 replicate cultures of each L. plantarum strain). 


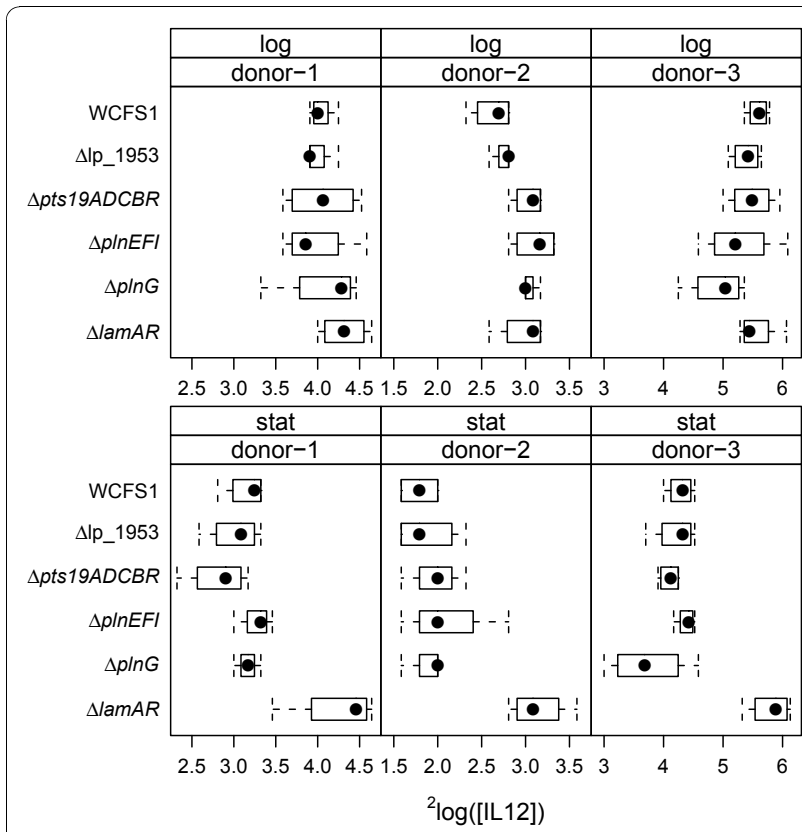

Figure 3 Boxplots of IL-12 amounts produced by PBMCs in response to $L$. plantarum wild-type and mutant cells. ${ }^{2} \mathrm{Log}$ transformed IL-12 amounts induced by exponential and stationary phase $L$. plantarum cells are shown. The dots indicate the median value, the boxes indicate first and third quartile, and the whiskers extend to outlying data points for a total of 12 measurements (3 PBMC donors were measured using 4 replicate cultures of each L. plantarum strain)

wild-type cells (Figure 4 and Table 3). These differences were observed only for wild-type and mutant cells harvested during exponential phase growth (adj. $\mathrm{p}$ value $=$ 0.005). Immunomodulation of the $\Delta \operatorname{lam} A \Delta \operatorname{lamR}$ mutant was also substantially different compared to

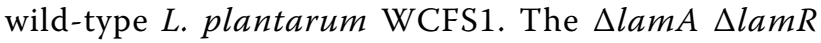
mutant induced significantly higher IL-10/IL-12 ratios $($ adj. $\mathrm{p}$ value $=0.016)$ and IL-12 $($ adj. $\mathrm{p}$ value $<0.001)$ and IL-10 (adj. p value < 0.001) amounts in PBMCs (Table 3). These effects were partially dependent on the growth-phase of the L. plantarum cells. IL-10/IL-12 ratios and IL-10 amounts induced by wild-type and mutant cells were significantly different when exponential phase cultures were used in the PBMC assay, whereas IL-10 and IL-12 amounts also differed when stationary-phase cells were examined (Figure 2, 3, 4 and Table 3).

In agreement with the gene trait matching correlations, the $\triangle p s t 19 A D C B R$ mutant induced significantly higher amounts of IL-10 than wild-type $L$. plantarum (adj. $\mathrm{p}$ value $=0.031$ ) (Figure 2 and Table 3 ). Similarly, the IL-10/IL-12 ratio was significantly higher $(\mathrm{p}<0.001)$ upon stimulation with L. plantarum $\triangle$ pst19ADCBR compared with the parental strain (Figure 4 and Table 3). L. plantarum strains harboring lp_1953 were also

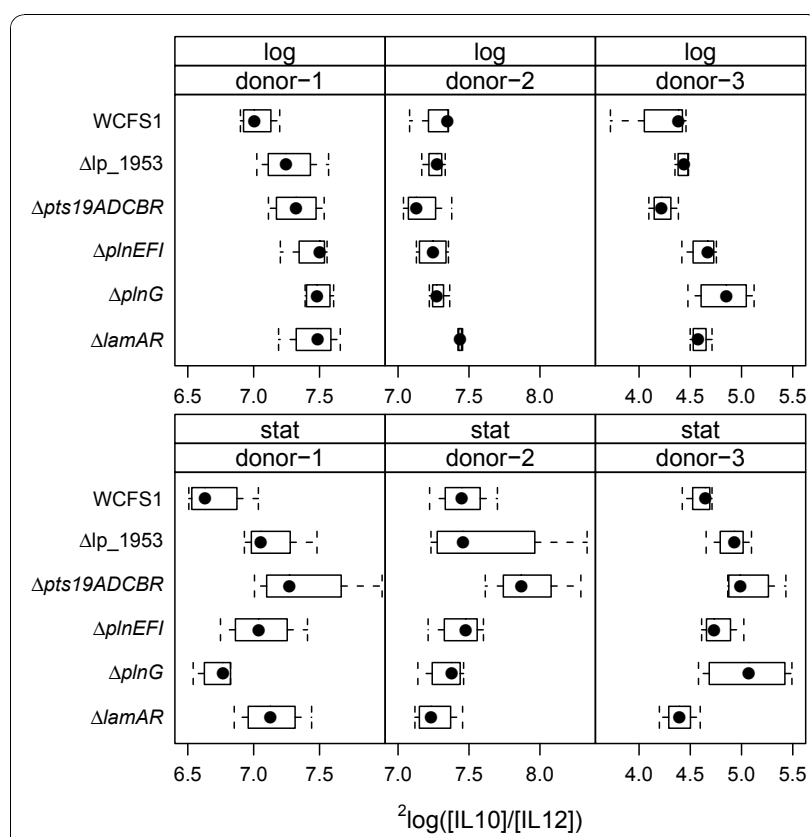

Figure 4 Boxplots of IL-10/IL-12 amounts produced by PBMCs in response to $L$. plantarum wild-type and mutant cells. ${ }^{2} \mathrm{Log}$ transformed IL-10/IL -12 ratios induced by exponential and stationary phase $L$. plantarum cells are shown. The dots indicate the median value, the boxes indicate first and third quartile, and the whiskers extend to outlying data points for a total of 12 measurements (3 PBMC donors were measured using 4 replicate cultures of each $L$. plantarum strain).

predicted to induce higher IL-10 production levels compared with strains lacking this gene. However, the L. plantarum lp_1953 deletion mutant stimulated equivalent amounts of IL-10 and somewhat higher IL-10/IL -12 ratios (adj. $\mathrm{p}$ value $=0.024$ ) relative to wild-type $L$. plantarum WCFS1 (Figure 4 and Table 3 ). Although the lp_1953 mutant induces a modest, yet significantly different, IL-10/IL-12 response relative to the parental strain, these results are not in agreement with the immunomodulatory effects predicted for this gene.

In summary, of the 5 mutants tested here, three $(\triangle l a m A \Delta l a m R, \triangle p s t 19 A D C B R$, and $\triangle p l n G)$ significantly affected the immune response of PBMCs in different donors according to the phenotypes predicted from the gene-trait matching data (Table 2). The plnEFI mutant also affected the immune response in the predicted manner but this was not significant considering the adjusted $\mathrm{p}$ value. The $\Delta \operatorname{lam} A \Delta \operatorname{lamR}$ mutant conferred the largest differences on the induction of IL-10 and IL12 and the IL-10/IL-12 ratio by L. plantarum (Table 3 ).

\section{Discussion}

This study demonstrated the diverse capacities of L. plantarum strains to stimulate cytokine production in human PBMCs and confirmed the contributions of 
Table 3 Relative differences in cytokine amounts between L. plantarum WCFS1 wild-type and deletion mutants.

\begin{tabular}{|c|c|c|c|c|c|c|c|c|c|c|}
\hline \multirow[b]{2}{*}{$\begin{array}{l}\text { Mutant } \\
\text { comparison }^{a}\end{array}$} & \multirow[b]{2}{*}{$\begin{array}{l}\text { Growth } \\
\text { phase }^{\text {b }}\end{array}$} & \multicolumn{3}{|c|}{ IL-10 } & \multicolumn{3}{|c|}{ IL-12 } & \multicolumn{3}{|c|}{ IL-10/IL-12 } \\
\hline & & value & $\mathrm{p}$-value & $\begin{array}{l}\text { adj. } p- \\
\text { value }\end{array}$ & value & $\mathrm{p}$-value & $\begin{array}{l}\text { adj. } p- \\
\text { value }\end{array}$ & value & $\mathrm{p}$-value & $\begin{array}{l}\text { adj. } p- \\
\text { value }\end{array}$ \\
\hline \multirow[t]{2}{*}{ Ip_1953 } & $\log$ & 0.097 & 0.461 & 0.830 & -0.041 & 0.775 & 0.825 & 0.138 & 0.161 & 0.803 \\
\hline & stat & 0.253 & 0.057 & 0.228 & -0.043 & 0.761 & 0.825 & 0.296 & 0.003 & 0.024 * \\
\hline \multirow[t]{2}{*}{$p t s 19 A D C B R$} & $\log$ & 0.164 & 0.216 & 0.647 & 0.106 & 0.458 & 0.825 & 0.058 & 0.556 & 0.923 \\
\hline & stat & 0.396 & 0.004 & $0.031 *$ & -0.131 & 0.371 & 0.825 & 0.529 & 0.000 & $0.000 * * *$ \\
\hline \multirow[t]{2}{*}{ plnEFI } & $\log$ & 0.287 & 0.031 & 0.176 & 0.032 & 0.825 & 0.825 & 0.255 & 0.010 & 0.071 \\
\hline & stat & 0.344 & 0.010 & 0.071 & 0.174 & 0.225 & 0.825 & 0.170 & 0.084 & 0.507 \\
\hline \multirow[t]{2}{*}{$p \ln G$} & $\log$ & 0.280 & 0.035 & 0.176 & -0.070 & 0.625 & 0.825 & 0.350 & 0.000 & $0.005 * *$ \\
\hline & stat & -0.028 & 0.830 & 0.830 & -0.146 & 0.307 & 0.825 & 0.118 & 0.230 & 0.921 \\
\hline \multirow[t]{2}{*}{$\operatorname{lam} A \operatorname{lam} R$} & $\log$ & 0.511 & 0.000 & $0.001 * * *$ & 0.199 & 0.165 & 0.825 & 0.312 & 0.002 & $0.016 *$ \\
\hline & stat & 1.331 & 0.000 & $0.000 * * *$ & 1.321 & 0.000 & $0.000 * * *$ & 0.009 & 0.923 & 0.923 \\
\hline
\end{tabular}

${ }^{a}$ L. plantarum WCFS1 deletion mutant measured in the PBMC assay.

${ }^{b}$ Phase of growth from which L. plantarum cells were harvested (log = exponential phase; stat = stationary phase).

c The value is the average difference in ${ }^{2}$ Log cytokine amounts induced by wild-type L. plantarum and mutant cells harvested in the same phase of growth (log or stat). A positive value indicates an increase in IL-10 levels produced by PBMCs in response to mutant $L$. plantarum compared to the wild-type cells. Calculations of $t$-test $p$-values and adjusted (adj.) p-values are described in the text (Materials and Methods). ${ }^{*}(0.01<p<0.05) ;{ }^{* *}(0.002<p<0.01) ;{ }^{* * *}(p<$ 0.002) for the adj. p-values.

specific L. plantarum genes to modulate these responses. Forty-two L. plantarum strains induced PBMCs to secrete IL-10 over an average 14-fold range. This range was similar to IL-10 amounts stimulated by 7 Bifidobacterium longum strains [43] and the 10 to 15fold differences in cytokine amounts induced in PBMCs by multiple Lactobacillus and Bifidobacterium species [7-11]. Moreover, we found that variation in IL-10 and IL-12 amounts and IL-10/IL-12 ratios induced by the distinct L. plantarum strains was higher than reported previously [44]. This result was probably due to the analysis of more strains in the present study (42 versus 3 ), which were isolated from diverse environmental niches encompassing a greater genetic and phenotypic diversity of the L. plantarum species. Such strain-specific differences should therefore be taken into consideration when selecting a probiotic Lactobacillus culture for health conditions which are dependent on modulating immunity such as in the prevention of allergy, eczema, or inflammatory bowel disease.

To identify L. plantarum genes with roles in modulating immune cell responses, L. plantarum genetic diversity was correlated with strain-specific capacities to induce cytokines in PBMCs. Genes with putative contributions to the observed PBMC responses were further investigated in L. plantarum WCFS1. A similar gene-trait matching approach previously resulted in the identification of a L. plantarum mannose-specific adhesin (Msa) [45] and genes which modulate dendritic cell responses [46]. Although the gene-trait matching approach has been successful, it should be recognized that only a subset of immunomodulatory cell components produced by L. plantarum was likely identified here. Firstly, the identified immunomodulatory genetic loci were restricted to genes in the L. plantarum WCFS1 reference strain genome. Secondly, genes with high levels of sequence conservation such that they are not distinguished by $\mathrm{CGH}$ (presence versus absence, rather than minor sequence variations) might be excluded from detection. For example, L. plantarum highly conserved LTA biosynthesis and modification genes known to have established effects on mammalian immunity were not found in this biodiversity-based gene-trait matching approach. Finally, genetic assessments do not take into account strain-specific variations in gene expression, translation, or post-translational modification of proteins with immunomodulatory effects.

Despite these limitations and the considerable variation in the production of cytokines by PBMCs from different donors, the present study demonstrated that gene-trait matching is also suitable for the identification of genes that affect cytokine levels in the mixture of immune cells collectively termed PBMCs. The products of AIP-based QS-TCSs and the N-acetyl-galactosamine/ glucosamine phosphotransferase system identified here might constitute a new class of bacterial cell products which are recognized by host receptors. The findings are significant because these genes were identified using intact cells which likely have multiple interactions with immune cells such that single genes only confer incremental effects.

L. plantarum WCFS1 lamB, a processing/export protein of the AIP-based QS-TCS LamBDCA [47], was correlated with immunomodulation of PBMCs. LamB, a transmembrane protein, is under the control of two response regulators $\operatorname{lam} A$ and $\operatorname{lamR}$ [40]. A L. plantarum $\triangle$ lamA $\triangle l a m R$ mutant investigated in this study was 
found to induce PBMCs to secrete significantly higher amounts of the cytokines IL-10 and IL-12. In a previous report, global transcript profiling of the lamA lamR deletion mutant showed that the $\operatorname{lamBDCA}$ system is auto-regulated and controls the production of several surface-associated proteins, stress-associated functions, and surface polysaccharides [40]. Higher amounts of surface polysaccharides produced by $L$. plantarum $\triangle$ lamA $\triangle l a m R$ decreased the biofilm-forming capacity of the mutant strain [40]. Polysaccharides produced by some Lactobacillus species are known for their immunomodulatory effects either by direct interactions with immune cells or by shielding MAMPs on the bacterial cell surface from detection by the immune system $[18,48,49]$. Therefore the observed PBMC IL-10/IL-12 ratios for L. plantarum might either be mediated directly through the LamBDCA system and the cognate secreted peptide, or indirectly through cell products (e.g., polysaccharides) under the control of this regulatory system. The latter is supported by the genetic similarities between LamBDCA and the Staphylococcus aureus agr system, an AIP-based QS-TCS which controls the evasion of innate host defenses by $S$. aureus through the production of secreted peptides and proteases [50].

The plantaricin biosynthesis pathway of L. plantarum WCFS1 is also controlled by an AIP-based QS-TCS [47] and genes required for plantaricin production and transport contributed to L. plantarum effects on PBMCs. Plantaricin is a bacteriocin composed of two small secreted peptides ( $p \ln E$ and $p \ln F$ ) which destabilize the integrity of the plasma membrane of susceptible cells [51]. L. plantarum strains harboring $p \ln E F$ and $p \ln I$ encoding a plantaricin immunity protein, and/or $p \ln G$ encoding a membrane bound $A B C$-transporter induced PBMCs to secrete IL-10 and IL-12 in amounts that yielded lower IL -10/IL-12 ratios (Table 2). Similarly, wild-type $L$. plantarum WCFS1 conferred lower IL-10/ IL-12 ratios compared to the $p \ln E F I$ and $p \ln G$ deletion mutants, although this was significant only for the $p \ln G$ mutant $(\mathrm{p}=0.005)$ and not the mutant lacking $p \ln E F I$ $(\mathrm{p}=0.071)$. The identification of the AIP plantaricin is intriguing because human antimicrobial peptides such as defensins secreted in the gut are known to modulate immune responses $[52,53]$ and suggest that antimicrobial peptides of bacterial origin might have similar capacities. These findings are also compatible with a recent study showing that plantaracins can modulate dendritic cell responses [46]. Moreover, several independent studies showed that L. plantarum WCFS1 genes involved plantaricin biosynthesis and activity, including $p \ln I$ and $p \ln F$, are induced in the mouse gut [30-32], thereby indicating that plantaricin production is active in the intestine where it might come into contact with mucosal immune cells.
Another of the confirmed genes with immunomodulatory capacities was the pts19ADCBR locus coding for a cell membrane-associated $\mathrm{N}$-acetyl-galactosamine/glucosamine phosphotransferase system. The relevance of the pts19ADCBR genes in adaptation to the intestinal ecosystem was also demonstrated by their higher expression levels in the intestine of conventionally-raised and germfree mice [31,32]. Moreover, in Lactobacillus johnsonii, a putative mannose phosphotransferase gene locus with $43 \%$ amino acid identity to the L. plantarum WCFS1 pts19ADCBR cluster was found to be important for long term persistence in vivo [54]. Although the regulatory signals for expression of these genes are unknown, immunomodulatory effects conferred by Pts19ADCBR might influence the ability of $L$. plantarum to modify the intestinal environment for survival in the gut.

Cytokine profiles of the lp_1953 deletion mutant were not in agreement with the IL-10 stimulating capacity predicted for this gene by gene-trait matching. This result exemplifies the need for mutation analysis to confirm gene-trait predictions, which are likely to encompass false-positive associations. A similar conclusion was drawn during the identification of the L. plantarum Msa gene [45]. Moreover, the product of lp_1953 is predicted to be intracellular, which contrasts the predicted subcellular location of all other genes examined here (secreted or cell envelope associated) [24,25]. This finding supports the notion that surface-localized proteins or components are the most likely candidate-participants in hostmicrobe interactions $[49,55]$. Thus far, the majority of the known immunomodulating MAMPs known for lactobacilli are extracellular or cell surface associated products such as LTA, exopolysaccharides, and peptidoglycan, although intracellular CpG-containing oligodeoxynucleotides (ODNs) produced by some lactobacilli are able to induce IL-10 production in immune cells $[21,49]$. These MAMPs are recognized by specific Pattern Recognition Receptors (PRRs) such as Toll-like receptors (TLRs) and nucleotide oligomerization domain (NOD)-like receptors [21]. To identify the mechanisms underlying the effects of AIP-based QS-TCSs and the N-acetyl-galactosamine/ glucosamine phosphotransferase system on immune cells, the cellular products encoded by the genes in these pathways should be investigated to identify the specific cell types among the PBMCs, which include lymphocytes, monocytes and macrophages, that recognize these compounds as well as the specific mechanisms leading to altered cytokine production.

Comparisons of mutant and wild-type L. plantarum WCFS1 cells included examination of the effects of culture growth phase on the stimulation of PBMCs. Exponential- and stationary-phase L. plantarum WCFS1 cultures were evaluated because the growth phase of probiotic cells was previously shown to influence the 
immune responses to probiotic bacteria in vitro [56-59] and in vivo [35]. Using human PBMCs, we found significant growth-phase dependent differences in the immunomodulatory capacities of the wild-type and mutant L. plantarum cultures. Collectively, the exponentialphase L. plantarum WCFS1 cultures stimulated higher absolute amounts of IL-10 and IL-12 and hence appear to induce heighted immune responses by PBMCs compared with stationary-phase cells. Notably, this result was not due to extensive $L$. plantarum growth because antibiotics were added to the PBMC growth medium to prevent bacterial overgrowth which would generate artifacts from acidification of the medium causing PBMC cell stress or death. Moreover, intact and lysed L. plantarum strains cells collected from the exponential and stationary phase of growth do not show striking differences in their TLR9 signaling activity and there was not a clear trend among all strains tested (personal observation, M. Meijerink and J. M. Wells). Therefore the higher amounts of cytokines induced by exponential phase bacteria are unlikely to be caused by differential cell lysis resulting in the release of intracellular $\mathrm{CpG}$ DNA, a known MAMP recognized by TLR9.

Comparisons of wild-type and mutant $L$. plantarum cultures also showed growth-phase dependent effects. The IL-10 amounts and IL-10/IL-12 ratios induced by the $p t s 19 A D C B R$ deletion mutant were significantly different from wild-type L. plantarum WCFS1 for only the stationary-phase cultures. Stationary-phase cells of the $\triangle l a m A \Delta l a m R$ mutant also induced significantly higher amounts of IL-10 and IL-12 in compared with L. plantarum WCFS1 harvested at the same growth phase. However, differences between IL-10/IL-12 ratios induced by $\Delta \operatorname{lam} A \Delta \operatorname{lamR}$ and wild-type cell differed only for exponential phase cultures. This result might have been partially due to the extensive alterations in expression of L. plantarum $\triangle \mathrm{l}$ amA $\triangle$ lamR in actively growing cultures [39], such that differences in expression of lamBDCA and $\operatorname{lam} K R$ regulated genes might have influenced the ability of the exponential-phase $L$. plantarum cells to stimulate different PBMC IL -10/IL -12 ratios. A similar result was found for the comparisons of L. plantarum $p \ln G$ (and $p \ln E F I$ ), the other 2 TCS system examined, although the specific growth-phase-dependent modifications of the plantaricin system on cytokine production in PBMCs is not presently known.

\section{Conclusions}

The present study compared the genetic and phenotypic diversity of $L$. plantarum WCFS1 to identify cell components of this species with the capacity to modulate human PBMC responses. We successfully identified several L. plantarum WCFS1 genes that are associated with the production of anti- and pro-inflammatory cytokines by
PBMCs and established that the immune response to L. plantarum can be significantly altered by the deletion of specific $L$. plantarum cell surface proteins. The increased IL-10/IL-12 ratios of the L. plantarum mutants indicate that these cultures would be more protective against intestinal inflammation compared with wild-type cells. These effects might be mediated by the down-regulation of local inflammatory responses through various subsets of $\mathrm{T}$ cells producing a collection anti-inflammatory cytokines. As a result of this study, strain selection for protection against intestinal inflammation might include screening for strains lacking the LamB, PlnG, or Pts19 homologs or by modifying culture growth conditions or food delivery matrices to minimize the expression of these genes in vivo. Such studies are required to distinguish between health effects conferred by individual probiotic strains and to develop methods to ensure that probiotic cells express host-modulatory cell products at the appropriate level and time in food products and the human gut.

\section{Methods}

\section{Bacterial strains}

Immune assays and genetic analysis was performed on a total of $42 \mathrm{~L}$. plantarum strains with distinct phenotypic profiles $[27,28]$ (Table 1). Comparative genome hybridization $(\mathrm{CGH})$ of these strains was performed previously $[27,28]$. For immunoprofiling, the L. plantarum strains were grown at $37^{\circ} \mathrm{C}$ in Mann-Rogusa Sharpe (MRS) broth (Merck, Darmstadt, Germany) until mid-exponential (optical density (OD) $600 \mathrm{~nm}=1$ ) phase or stationary phase $(24 \mathrm{~h}$ after the start of the culture, OD600 $\mathrm{nm}=$ $7.6 \pm 1.1$ ) [60]. The exponential and stationary phase cells were washed twice in phosphate buffered saline (PBS) at $\mathrm{pH} 7.4$, suspended at $2 \times 10^{8}$ cells $/ \mathrm{ml}$ in PBS containing $20 \%$ glycerol, and stored at $-80^{\circ} \mathrm{C}$ until co-culturing with human immune cells. Quantification of the exponential and stationary phase viable cells before and after freezing showed no significant losses in cell viability (data not shown). Colony forming units (CFUs) were determined by plating serial dilutions of the cultures on MRS agar (data not shown).

\section{Peripheral blood mononuclear cells assay}

This study was approved by Wageningen University Ethical Committee and was performed according to the principles of the Declaration of Helsinki. Peripheral blood of healthy donors was from the Sanquin Blood Bank, Nijmegen, The Netherlands. Before sample collection, a written informed consent was provided. Peripheral blood mononuclear cells (PBMCs) were separated from the blood of healthy donors using Ficoll-Paque Plus gradient centrifugation according to the manufacturer's protocol (Amersham biosciences, Uppsala, 
Sweden). After centrifugation the mononuclear cells were collected, washed in Iscove's Modified Dulbecco's Medium (IMDM) + glutamax (Invitrogen, Breda, The Netherlands) and adjusted to $1 \times 10^{6}$ cells $/ \mathrm{ml}$ in IMDM + glutamax supplemented with penicillin $(100 \mathrm{U} / \mathrm{ml})$ (Invitrogen), streptomycin $(100 \mu \mathrm{g} / \mathrm{ml})$ (Invitrogen), and $1 \%$ human AB serum (Lonza, Basel, Switzerland). PBMCs $(1 \times$ $10^{6}$ cells/well) were seeded in 48-well tissue culture plates. After an overnight rest at $37^{\circ} \mathrm{C}$ in $5 \% \mathrm{CO}_{2}, 5 \mu \mathrm{l}$ aliquots of thawed bacterial suspensions at $2 \times 10^{8} \mathrm{CFU} / \mathrm{ml}$ were added to the PBMCs (L. plantarum: PBMC ratio of 1:1). PBS $(5 \mu \mathrm{l})$ and LPS $(1 \mu \mathrm{g})$ served as negative (PBS) and positive (LPS, TLR4 ligand) controls for the stimulation of PBMCs. IL-10 was produced in sufficient amounts for quantification in response to LPS but not to PBS. Similarly, neither LPS nor the PBS buffer stimulated the production of IL-12. To test the capacity of the $42 \mathrm{~L}$. plantarum strains to stimulate PBMC cytokine production, PBMCs from 3 different donors were examined (donors $\mathrm{A}, \mathrm{B}$, and $\mathrm{C}$ ). For donors $\mathrm{A}$ and $\mathrm{B}$, separate stationaryphase cultures of each $L$. plantarum strain were used. For donor C, both replicate cultures of each L. plantarum strain were examined. In PBMC assays comparing responses to $L$. plantarum WCFS1 wild-type and mutant strains, PBMCs from 3 different donors were examined using 4 independent replicate wild-type and mutant L. plantarum cultures harvested during exponential-phase and stationary-phase of growth.

Following $24 \mathrm{hr}$ incubation at $37^{\circ} \mathrm{C}$ in $5 \% \mathrm{CO}_{2}$, culture supernatants were collected and stored at $-20^{\circ} \mathrm{C}$ until cytokine analysis. This time point was selected for analysis because previous studies showed that IL-12 levels remain unaltered after 4 days of $L$. plantarum incubation with PBMCs. Although IL-10 was shown to increase 2- fold after 4 days of co-incubation with L. plantarum, sufficient cytokine amounts were produced after $24 \mathrm{~h}$ to permit flow cytometric measurements [61]. No viable bacteria could be cultured and medium acidification was not observed after incubation of $L$. plantarum strains with the PBMCs for $24 \mathrm{~h}$ (data not shown). Cytokines were measured using a FACS CantoII flow cytometer (BD Biosciences, Franklin Lakes, New Jersey) and BD Cytometric Bead Array Flexsets (BD Biosciences) for interleukin (IL)-10 and IL-12p70 (henceforth referred to as IL-12) according to the manufacturer's recommendations. Detection limits were 0.13 and $0.6 \mathrm{pg} / \mathrm{ml}$ for IL-10 and IL-12 respectively. Concentrations of analytes were calculated with the use of known standards and plotting the sample values against a standard curve in the BD Biosciences FCAP software. Donor-specific variation in cytokine production capacities was taken into account by dividing the cytokine amounts induced by individual $L$. plantarum strains against average cytokine quantities induced by all
L. plantarum strains for the same donor. These values were then compared to amounts induced by L. plantarum WCFS1 and used for gene-trait matching.

\section{Identification of candidate genes involved in cytokine secretion by gene-trait matching}

L. plantarum genes with potential roles in modulating of PBMC cytokine production were identified by in silico matching using genotype information referenced from the L. plantarum WCFS1 genome (also termed gene-trait matching) [45]. Individual L. plantarum WCFS1 gene presence or absence scores for the 42 strains were used as putative predictor variables for PBMC induced IL-10, IL-12 and IL-10/IL-12 amounts by regression using the Random Forest algorithm [38]. The "RandomForest" package for $\mathrm{R}$ [62] was used with standard parameter settings. L. plantarum WCFS1 genes with the highest variable importance measures by the Random Forest method were selected for deletion analysis.

\section{Construction of L. plantarum WCFS1 gene deletion mutants}

A previously described $L$. plantarum $\triangle l a m A \Delta l a m R$ mutant was used in this study [40]. Construction of L. plantarum lp_1953, lp_2647-2651, lp_0419-0422 and lp_0423 gene deletion mutants was performed as previously described [63] with several modifications. The mutagenesis vectors were generated by a splicing by overlap extension (SOE) procedure [64]. This procedure was designed to expedite mutagenesis vector construction for L. plantarum using a single step, blunt-ended cloning and positive selection for transformants based on chloramphenicol resistance. PCR was used to amplify approximately $1 \mathrm{~kb}$ of the 5' and 3' regions flanking the genes targeted for deletion (for primer sequences see Table 4). In addition, the loxP-cat-loxP region of pNZ5319 was amplified using primers Ecl-loxR and Pml-loxF (Table 4). For each mutagenesis vector, the amplicons representing the corresponding 2 flanking regions and the loxP-cat-loxP region were mixed in a 1:1:1 molar ratio and used as template in a second PCR reaction with the 5 'forward and 3'reverse flanking primers. These PCR reactions resulted in $3 \mathrm{~kb}$ amplicons which were cloned into the integration vector pNZ5319 [63] after prior digestion of the vector with SwaI and Ecl136II. Plasmids were transformed into competent cells of E. coli JM109 by electroporation as recommended by the manufacturer (Invitrogen). Plasmid DNA was isolated from E. coli using Jetstar columns (Genomed GmbH, Bad Oeynhausen, Germany) using the manufacturer's recommended protocol. DNA sequencing (BaseClear, Leiden, The Netherlands) was performed to confirm the integrity of the cloned genes. 
Table 4 Primers used in this study.

\begin{tabular}{|c|c|}
\hline Primer & Sequence $^{\mathrm{a}}$ \\
\hline LF1953F & 5'- TGCCGCATACCGAGTGAGTAG-3' \\
\hline LF1953R & 5'-CGAACGGTAGATTTAAATTGTTTATCAAAAAACACCGTTAATTTGCATC-3' \\
\hline RF1953F & 5'-GTACAGCCCGGGCATGAGCGTGGCCATTAGTTGACGAGAC-3' \\
\hline RF1953R & $5^{\prime}-\mathrm{AACGCCATCGCACTGATGCATC-3^{ \prime }}$ \\
\hline Ecl-loxR & 5'-AAACAATTTAAATCTACCGTTCG-3' \\
\hline Pml-loxF & 5'-CTCATGCCCGGGCTGTAC-3' \\
\hline LF1953F2 & 5'-GCAACGGCTGTCAGTAACCTGCCTTC-3' \\
\hline RF1953R2 & 5'-TCAAATCTCGAAGCGGTTCAAAACTG-3' \\
\hline LF2647F & 5'-GTACAGCCCGGGCATGAGGGTATTTAGCGAAATATACAGATTG-3' \\
\hline LF2647R & 5'-CTTTAGCCGTCTCATTAGTCG-3' \\
\hline RF2651F & 5'-GGATTACCAAAACGAACATGG-3' \\
\hline RF2651R & 5'-CGAACGGTAGATTTAAATTGTTTACTAGCCATTITGTITTATCTCC-3' \\
\hline LF2647R2 & $5^{\prime}-\overline{T G A C A T G A C T A T C C T G A C T T G C-3^{\prime}}$ \\
\hline RF2651F2 & 5'-AACGTTCAACGGCAGATAAGCC-3' \\
\hline LF423F & 5'-AATTGATACATGTGGTTTCGAAAG-3' \\
\hline LF423R & 5'-CGAACGGTAGATTTAAAATTGTTTCCAATGCATACTTGTACTCCC-3' \\
\hline RF423F & 5'-GTACAGCCCGGGCATGAG CGACTTGATCAATAGCTGAGGG-3' \\
\hline RF423R & 5'-TTGGTTGCCTTGATCGTGTAAG-3' \\
\hline LF423F2 & 5'-CTTCAGTTATCGCTACAATCAACG-3' \\
\hline RF423R2 & 5'-ACTAACGTACTTTGCACCACGG-3' \\
\hline LF419F & 5'-GTACAGCCCGGGCATGAGGACGAGTAATCATCCATTCTGA-3' \\
\hline LF419R & 5'-ATGAGTTTGCAATGGAGCTTAGG-3' \\
\hline RF422F & 5'-CAAAGACGTGCCGAATATAGCC-3' \\
\hline RF422R & 5'-CGAACGGTAGATTTAAATTGTTTAAACTGTAGCATAAATAATCCCC-3' \\
\hline LF419R2 & 5'-GAGATAATTATTGTAAGACCGTC-3' \\
\hline RF422F2 & 5'-CTAACGCATCAATAATCTTACTGG-3' \\
\hline
\end{tabular}

${ }^{a}$ Bold and underlined nucleotides signify overlapping ends with the Ecl-loxR and Pml-loxF primers.

The resulting plasmids containing the complete gene replacement cassettes were used for mutagenesis [63].

\section{Statistical analysis}

Linear mixed effect models using restricted maximum likelihood (REML) were used to statistically compare the mean cytokine values of IL-10, IL-12, and IL-10/IL12 produced in response to $L$. plantarum wild-type and mutant cells. The effect of the donor on the response variable was modeled as a random effect. The fixed effects in the model were the strains (WCFS1 [wild type], $\triangle p t s 19 A D C B R, \Delta$ lp_1953, $\Delta p \ln G, \Delta p \ln E F I$, and $\triangle l a m A \Delta \operatorname{lamR})$ and the growth phase at the time of harvest (exponential phase and stationary phase). Logarithmic transformations of [IL-10], [IL-12] and [IL-10]/ [IL-12] yielded residuals that showed approximately normal distributions (data not shown) and, hence, were used as the response variables in the fitting procedure. Statistical analysis was performed using R http://www.rproject.org, with the package "nlme" [65] for mixed effect modeling. The donor random effect was modeled as a constant offset relative to the average level of the response variable ("model 1"), or alternatively, as a donor-dependent offset plus a donor-dependent variation in the effect of the bacterial growth phase on the response variable ("model 2"). Model 2 yielded better fits for ${ }^{2} \log \left(\left[\right.\right.$ IL-10]) and ${ }^{2} \log ([\mathrm{IL}-10] /[\mathrm{IL}-12])$ response variables whereas, indications of a donor dependent variation in growth phase effects were not found for the ${ }^{2} \log ([\mathrm{IL}-12])$ response, and hence model 1 was applied for comparison of these cytokine amounts. The resulting relative difference coefficients and $t$ tests were calculated from the fixed effects (mutation, growth phase, and their interaction) using analysis of variance in $\mathrm{R}$. The $\mathrm{p}$-values were adjusted for multiple hypothesis testing using the correction procedures by Hochberg [66].

\footnotetext{
Acknowledgements

We would like to thank Nico Taverne for his assistance with the immune assays. This work was funded by TI Food \& Nutrition, Wageningen, The Netherlands.

\section{Author details}

${ }^{1}$ TI Food \& Nutrition, Nieuwe Kanaal 9A, 6709PA, Wageningen, The Netherlands. ${ }^{2} \mathrm{NIZO}$ food research, P.O. Box 20, 6710 BA Ede, The Netherlands. ${ }^{3}$ Host-Microbe Interactomics, Animal Sciences, Wageningen University, P.O. Box 338, 6700 AH Wageningen, The Netherlands. ${ }^{4}$ Vrije
} 
Universiteit Amsterdam, Faculty of Earth and Life Sciences, De Boelelaan 1085, 1081 HV Amsterdam, The Netherlands. ${ }^{5}$ Kluyver Centre for Genomics of Industrial Fermentation, P.O. Box 5057, 2600 GA, Delft, The Netherlands. ${ }^{6}$ Immunoendocrinology, Pathology and Medical Biology, University Medical Centre Groningen, Hanzeplein 1, 9700 RB Groningen, The Netherlands. ${ }^{2}$ Laboratory of Microbiology, Wageningen University, Dreijenplein 10, 6703 HB Wageningen, The Netherlands. ${ }^{8}$ Department of Food Science and Technology, One Shields Avenue, Davis, CA 95616, USA.

\section{Authors' contributions}

$\mathrm{SvH}$ performed the PBMC assays, constructed the deletion mutants and prepared the manuscript. MM assisted with isolation of PBMCs and flow cytometry for cytokine analysis. DM performed the statistical analysis and gene-trait matching. PB designed the mutagenesis strategy. PdV coordinated the research groups involved in the study and assisted in data interpretation and analysis. MK assisted with the design of the study and help draft the manuscript. JMW helped draft the manuscript, assisted with the design of the study, and supervised a portion of the research. MLM designed the study, supervised a portion of the research, and prepared the manuscript. All authors read and approved the final manuscript.

Received: 5 July 2010 Accepted: 16 November 2010

Published: 16 November 2010

\section{References}

1. Neish AS: Microbes in gastrointestinal health and disease. Gastroenterology 2009, 136(1):65-80

2. Turnbaugh PJ, Hamady M, Yatsunenko T, Cantarel BL, Duncan A, Ley RE, Sogin ML, Jones WJ, Roe BA, Affourtit JP, et al: A core gut microbiome in obese and lean twins. Nature 2009, 457(7228):480-484.

3. Sanders ME, Marco ML: Food formats for effective delivery of probiotics. Ann Rev Food Sci Technol 2010, 1:65-85.

4. Floch MH, Walker WA, Guandalini S, Hibberd P, Gorbach S, Surawicz C, Sanders ME, Garcia-Tsao G, Quigley EM, Isolauri E, et al: Recommendations for probiotic use-2008. I Clin Gastroenterol 2008, 42(Suppl 2):S104-108.

5. Sanders ME: Probiotics: Considerations for human health. Nut Rev 2003, 61(3):91-99.

6. Marco ML, Pavan S, Kleerebezem M: Towards understanding molecular modes of probiotic action. Curr Opin Biotechnol 2006, 17(2):204-210.

7. Borchers AT, Selmi C, Meyers FJ, Keen CL, Gershwin ME: Probiotics and immunity. J Gastroenterol 2009, 44(1):26-46.

8. Niers LEM, Timmerman HM, Rijkers GT, van Bleek GM, van Uden NOP, Knol EF, Kapsenberg ML, Kimpen JLL, Hoekstra MO: Identification of strong interleukin-10 inducing lactic acid bacteria which down-regulate T helper type 2 cytokines. Clin Exp Allergy 2005, 35(11):1481-1489.

9. Miettinen M, VuopioVarkila J, Varkila K: Production of human tumor necrosis factor alpha, interleukin-6, and interleukin- 10 is induced by lactic acid bacteria. Infect Immun 1996, 64(12):5403-5405.

10. Foligne B, Nutten S, Grangette C, Dennin V, Goudercourt D, Poiret S, Dewulf J, Brassart D, Mercenier A, Pot B: Correlation between in vitro and in vivo immunomodulatory properties of lactic acid bacteria. World $J$ Gastroenterol 2007, 13(2):236-243.

11. Miettinen M, Matikainen S, Vuopio-Varkila J, Pirhonen J, Varkila K, Kurimoto $\mathrm{M}$, Julkunen I: Lactobacilli and streptococci induce interleukin12 (IL-12), IL-18, and gamma interferon production in human peripheral blood mononuclear cells. Infect Immun 1998, 66(12):6058-6062.

12. Kwon HK, Lee CG, So JS, Chae CS, Hwang JS, Sahoo A, Nam JH, Rhee JH, Hwang KC, Im SH: Generation of regulatory dendritic cells and CD4 +Foxp3+ T cells by probiotics administration suppresses immune disorders. Proc Natl Acad Sci USA 2010, 107(5):2159-2164

13. Karczewski J, Troost FJ, Konings I, Dekker J, Kleerebezem M, Brummer RJ, Wells JM: Regulation of human epithelial tight junction proteins by Lactobacillus plantarum in vivo and protective effects on the epithelial barrier. Am J Physiol Gastrointest Liver Physiol 2010, 298(6):G851-859.

14. Kim HG, Gim MG, Kim JY, Hwang HJ, Ham MS, Lee JM, Hartung T, Park JW, Han SH, Chung DK: Lipoteichoic acid from Lactobacillus plantarum elicits both the production of interleukin-23p19 and suppression of pathogenmediated interleukin-10 in THP-1 cells. FEMS Immunol Med Microbiol 2007, 49(2):205-214

15. Ryu YH, Baik JE, Yang JS, Kang SS, Im J, Yun CH, Kim DW, Lee K, Chung DK, $J u$ HR, et al: Differential immunostimulatory effects of Gram-positive bacteria due to their lipoteichoic acids. Int Immunopharmacol 2009, 9(1):127-133.

16. Matsuguchi T, Takagi A, Matsuzaki T, Nagaoka M, Ishikawa K, Yokokura T, Yoshikai Y: Lipoteichoic acids from Lactobacillus strains elicit strong tumor necrosis factor alpha-inducing activities in macrophages through Toll-like receptor 2. Clin Diagn Lab Immunol 2003, 10(2):259-266.

17. Yan F, Cao H, Cover TL, Whitehead R, Washington MK, Polk DB: Soluble proteins produced by probiotic bacteria regulate intestinal epithelial cell survival and growth. Gastroenterology 2007, 132(2):562-575.

18. Yasuda E, Serata M, Sako T: Suppressive effect on activation of macrophages by Lactobacillus casei strain Shirota genes determining the synthesis of cell wall-associated polysaccharides. Appl Environ Microbiol 2008, 74(15):4746-4755.

19. Konstantinov SR, Smidt H, de Vos WM, Bruijns SC, Singh SK, Valence F, Molle D, Lortal S, Altermann E, Klaenhammer TR, et al: S layer protein A of Lactobacillus acidophilus NCFM regulates immature dendritic cell and T cell functions. Proc Natl Acad Sci USA 2008, 105(49):19474-19479.

20. Kleerebezem M, Hols P, Bernard E, Rolain T, Zhou M, Siezen RJ, Bron PA: The extracellular biology of the lactobacilli. FEMS Microbiol Rev 2010, 34(2):199-230

21. Lebeer S, Vanderleyden J, De Keersmaecker SC: Host interactions of probiotic bacterial surface molecules: comparison with commensals and pathogens. Nat Rev Microbiol 2010, 8(3):171-184

22. de Vries MC, Vaughan EE, Kleerebezem M, de Vos WM: Lactobacillus plantarum- survival, functional and potential probiotic properties in the human intestinal tract. Int Dairy J 2006, 16(9):1018-1028.

23. Kleerebezem M, Boekhorst J, van Kranenburg R, Molenaar D, Kuipers OP, Leer R, Tarchini R, Peters SA, Sandbrink HM, Fiers M, et al: Complete genome sequence of Lactobacillus plantarum WCFS1. Proc Natl Acad Sci USA 2003, 100(4):1990-1995.

24. Boekhorst J, Wels M, Kleerebezem M, Siezen RJ: The predicted secretome of Lactobacillus plantarum WCFS1 sheds light on interactions with its environment. Microbiology 2006, 152(11):3175-3183.

25. Zhou M, Boekhorst J, Francke C, Siezen RJ: LocateP: genome-scale subcellular-location predictor for bacterial proteins. BMC Bioinformatics 2008, 9:173.

26. Teusink B, van Enckevort FHJ, Francke C, Wiersma A, Wegkamp A, Smid EJ, Siezen RJ: In silico reconstruction of the metabolic pathways of Lactobacillus plantarum: Comparing predictions of nutrient requirements with those from growth experiments. Appl Environ Microbiol 2005, 71(11):7253-7262.

27. Molenaar D, Bringel F, Schuren FH, de Vos WM, Siezen RJ, Kleerebezem M Exploring Lactobacillus plantarum genome diversity by using microarrays. J Bacteriol 2005, 187(17):6119-6127.

28. Siezen RJ, Tzeneva VA, Castioni A, Wels M, Phan HTK, Rademaker JLW, Starrenburg MJC, Kleerebezem M, Molenaar D, van Hylckama Vlieg JET: Phenotypic and genomic diversity of Lactobacillus plantarum strains isolated from various environmental niches. Environmental Microbiology 2010, 12(3):758-773.

29. Vesa T, Pochart P, Marteau P: Pharmacokinetics of Lactobacillus plantarum NCIMB 8826, Lactobacillus fermentum KLD and Lactococcus lactis MG 1363 in the human gastrointestinal tract. Aliment Pharmacol Ther 2000 14(6):823-828.

30. Marco ML, Bongers RS, de Vos WM, Kleerebezem M: Spatial and temporal expression of Lactobacillus plantarum genes in the gastrointestinal tracts of mice. Appl Environ Microbiol 2007, 73(1):124-132.

31. Bron PA, Grangette C, Mercenier A, de Vos WM, Kleerebezem M: Identification of Lactobacillus plantarum genes that are induced in the gastrointestinal tract of mice. J Bacteriol 2004, 186(17):5721-5729.

32. Marco ML, Peters THF, Bongers RS, Molenaar D, Van Hemert $S$, Sonnenburg JL, Gordon JI, Kleerbezem M: Lifestyle of Lactobacillus plantarum in the mouse cecum. Environ Microbiol 2009, 11(10):2747-2757.

33. Bron PA, Meijer M, Bongers RS, de Vos WM, Kleerebezem M: Dynamics of competitive population abundance of Lactobacillus plantarum ivi gene mutants in faecal samples after passage through the gastrointestinal tract of mice. J Appl Microbiol 2007, 103(5):1424-1434.

34. Marco ML, de Vries MC, Wels M, Molenaar D, Mangell P, Ahrne S, de Vos WM, Vaughan EE, Kleerebezem M: Convergence in probiotic Lactobacillus gut-adaptive responses in humans and mice. ISME J 2010, 4(11):1481-4. 
35. van Baarlen P, Troost FJ, van Hemert S, van der Meer C, de Vos WM, de Groot PJ, Hooiveld GJ, Brummer RJ, Kleerebezem M: Differential NF-kappaB pathways induction by Lactobacillus plantarum in the duodenum of healthy humans correlating with immune tolerance. Proc Natl Acad Sci USA 2009, 106(7):2371-2376.

36. Troost FJ, van Baarlen P, Lindsey $P$, Kodde $A$, de Vos WM, Kleerebezem M, Brummer RJ: Identification of the transcriptional response of human intestinal mucosa to Lactobacillus plantarum WCFS1 in vivo. BMC Genomics 2008, 9:374.

37. Yaqoob P, Newsholme EA, Calder PC: Comparison of cytokine production in cultures of whole human blood and purified mononuclear cells. Cytokine 1999, 11(8):600-605.

38. Breiman L: Random forests. Machine Learning 2001, 45(1):5-32.

39. Sturme MH, Nakayama J, Molenaar D, Murakami Y, Kunugi R, Fujii T, Vaughan EE, Kleerebezem M, de Vos WM: An agr-like two-component regulatory system in Lactobacillus plantarum is involved in production of a novel cyclic peptide and regulation of adherence. J Bacteriol 2005, 187(15):5224-5235.

40. Fujii T, Ingham C, Nakayama J, Beerthuyzen M, Kunuki R, Molenaar D, Sturme M, Vaughan E, Kleerbezem M, de Vos W: Two homologous agr-like quorum sensing systems co-operatively control adherence, cell morphology, and cell viability properties in Lactobacillus plantarum WCFS1. J Bacteriol 2008, 190(23):7655-7665.

41. Diep DB, Havarstein LS, Nes IF: Characterization of the locus responsible for the bacteriocin production in Lactobacillus plantarum C11. J Bacteriol 1996, 178(15):4472-4483.

42. Ventura M, Canchaya $C$, Kleerebezem M, de Vos WM, Siezen RJ, Brussow H: The prophage sequences of Lactobacillus plantarum strain WCFS1. Virology 2003, 316(2):245-255

43. Medina M, Izquierdo E, Ennahar S, Sanz Y: Differential immunomodulatory properties of Bifidobacterium logum strains: relevance to probiotic selection and clinical applications. Clin Exp Immunol 2007, 150(3):531-538.

44. Wang B, Li J, Li Q, Zhang H, Li N: Isolation of adhesive strains and evaluation of the colonization and immune response by Lactobacillus plantarum L2 in the rat gastrointestinal tract. Int J Food Microbiol 2009, 132(1):59-66.

45. Pretzer G, Snel J, Molenaar D, Wiersma A, Bron PA, Lambert J, de Vos WM, van der Meer R, Smits MA, Kleerebezem M: Biodiversity-based identification and functional characterization of the mannose-specific adhesin of Lactobacillus plantarum. Journal of Bacteriology 2005, 187(17):6128-6136

46. Meijerink $M$, van Hemert $S$, Taverne $N$, Wels $M$, de Vos P, Bron PA Savelkoul HF, van Bilsen J, Kleerebezem M, Wells JM: Identification of genetic loci in Lactobacillus plantarum that modulate the immune response of dendritic cells using comparative genome hybridization. PLoS One 2010, 5(5):e10632.

47. Sturme MH, Francke C, Siezen RJ, de Vos WM, Kleerebezem M: Making sense of quorum sensing in lactobacilli: a special focus on Lactobacillus plantarum WCFS1. Microbiology 2007, 153(Pt 12):3939-3947.

48. Vinderola G, Perdigon G, Duarte J, Farnworth E, Matar C: Effects of the oral administration of the exopolysaccharide produced by Lactobacillus kefiranofaciens on the gut mucosal immunity. Cytokine 2006, 36(56):254-260.

49. Lebeer S, Vanderleyden J, De Keersmaecker SC: Genes and molecules of lactobacilli supporting probiotic action. Microbiol Mol Biol Rev 2008, 72(4):728-764.

50. Kong KF, Vuong C, Otto M: Staphylococcus quorum sensing in biofilm formation and infection. Int J Med Microbiol 2006, 296(2-3):133-139.

51. Diep DB, Straume D, Kjos M, Torres C, Nes IF: An overview of the mosaic bacteriocin pln loci from Lactobacillus plantarum. Peptides 2009 30(8):1562-1574.

52. Yang D, Biragyn A, Hoover DM, Lubkowski J, Oppenheim JJ: Multiple roles of antimicrobial defensins, cathelicidins, and eosinophil-derived neurotoxin in host defense. Annu Rev Immunol 2004, 22:181-215.

53. Funderburg N, Lederman MM, Feng Z, Drage MG, Jadlowsky J, Harding CV, Weinberg A, Sieg SF: Human-defensin-3 activates professional antigenpresenting cells via Toll-like receptors 1 and 2. Proc Natl Acad Sci USA 2007, 104(47):18631-18635.

54. Denou E, Pridmore RD, Berger B, Panoff JM, Arigoni F, Brussow H: Identification of genes associated with the long-gut-persistence phenotype of the probiotic Lactobacillus johnsonii strain NCC533 using a combination of genomics and transcriptome analysis. J Bacterio/ 2008 190(9):3161-3168.

55. Sanchez B, Bressollier P, Urdaci MC: Exported proteins in probiotic bacteria: adhesion to intestinal surfaces, host immunomodulation and molecular cross-talking with the host. FEMS Immunol Med Microbiol 2008 54(1):1-17

56. Maassen CBM, Boersma WJA, van Holten-Neelen C, Claassen E, Laman JD: Growth phase of orally administered Lactobacillus strains differentially affects lgG1/lgG2a ratio for soluble antigens: implications for vaccine development. Vaccine 2003, 21(21-22):2751-2757.

57. Foligne B, Dewulf J, Breton J, Claisse O, Lonvaud-Funel A, Pot B: Probiotic properties of non-conventional lactic acid bacteria: immunomodulation by Oenococcus oeni. Int J Food Microbiol 2010, 140(2-3):136-145.

58. Haller D, Bode C, Hammes WP: Cytokine secretion by stimulated monocytes depends on the growth phase and heat treatment of bacteria: a comparative study between lactic acid bacteria and invasive pathogens. Microbiol Immunol 1999, 43(10):925-935.

59. Sashihara T, Sueki N, Furuichi K, Ikegami S: Effect of growth conditions of Lactobacillus gasseri OLL2809 on the immunostimulatory activity for production of interleukin-12 (p70) by murine splenocytes. Int J Food Microbiol 2007, 210(3):274-281.

60. Stevens MJA, Wiersma A, de Vos WM, Kuipers OP, Smid EJ, Molenaar D, Kleerebezem M: Improvement of Lactobacillus plantarum aerobic growth as directed by comprehensive transcriptome analysis. Appl Environ Microbiol 2008, 74(15):4776-4778.

61. Vissers YM, Snel J, Zuurendonk PF, Smit BA, Wichers HJ, Savelkoul HF: Differential effects of Lactobacillus acidophilus and Lactobacillus plantarum strains on cytokine induction in human peripheral blood mononuclear cells. FEMS Immunol Med Microbiol 2010, 59(1):60-70.

62. Liaw $\mathrm{A}$, Wiener $\mathrm{M}$ : Classification and regression by randomForest. $R$ news 2002, 2:18-22 [http://www.r-project.org].

63. Lambert JM, Bongers RS, Kleerebezem M: Cre-lox-based system for multiple gene deletions and selectable-marker removal in Lactobacillus plantarum. Appl Environ Microbiol 2007, 73(4):1126-1135.

64. Horton RM, Cai ZL, Ho SN, Pease LR: Gene splicing by overlap extension: tailor-made genes using the polymerase chain reaction. Biotechniques 1990, 8(5):528-535

65. Pinheiro J, Bates D: Mixed-effects models in S and S-plus. New York: Springer-Verlag; 2000.

66. Hochberg Y: A sharper Bonferroni procedure for multiple tests of significance. Biometrika 1988, 75(4):800-802.

doi:10.1186/1471-2180-10-293

Cite this article as: van Hemert et al:: Identification of Lactobacillus plantarum genes modulating the cytokine response of human peripheral blood mononuclear cells. BMC Microbiology 2010 10:293.

\section{Submit your next manuscript to BioMed Central and take full advantage of:}

- Convenient online submission

- Thorough peer review

- No space constraints or color figure charges

- Immediate publication on acceptance

- Inclusion in PubMed, CAS, Scopus and Google Scholar

- Research which is freely available for redistribution 